\title{
siRNA potency enhancement via chemical modifications of nucleotide bases at the $5^{\prime}$-end of the siRNA guide strand
}

\author{
FUMIKAZU SHINOHARA, ${ }^{1,2,3}$ TAIJI OASHI, ${ }^{1}$ TOSHIMASA HARUMOTO, ${ }^{1}$ TOMOYUKI NISHIKAWA, ${ }^{1}$ \\ YUKI TAKAYAMA, ${ }^{1}$ HIKARU MIYAGI, ${ }^{1}$ YUICHI TAKAHASHI, ${ }^{1}$ TAKAHIRO NAKAJIMA, ${ }^{1}$ TAKASHI SAWADA, \\ YASUO KODA, ${ }^{1}$ ASANA MAKINO, ${ }^{1}$ ATSUKO SATO, ${ }^{1}$ KAORI HAMAGUCHI, ${ }^{1}$ MICHIHIKO SUZUKI, ${ }^{1}$ \\ JUNICHIRO YAMAMOTO, ${ }^{1}$ YUKIHIDE TOMARI, ${ }^{2,3}$ and JUN-ICHI SAITO ${ }^{1}$ \\ ${ }^{1}$ Research Function Unit, R\&D Division, Kyowa Kirin Co. Ltd., Chiyoda-ku, Tokyo 100-0004, Japan \\ ${ }^{2}$ Laboratory of RNA Function, Institute for Quantitative Biosciences, The University of Tokyo, Bunkyo-ku, Tokyo 113-0032, Japan \\ ${ }^{3}$ Department of Computational Biology and Medical Sciences, Graduate School of Frontier Sciences, The University of Tokyo, Bunkyo-ku, \\ Tokyo 113-0032, Japan
}

\begin{abstract}
Small interfering RNAs (siRNAs) can be utilized not only as functional biological research tools but also as therapeutic agents. For the clinical use of siRNA as drugs, various chemical modifications have been used to improve the activity of siRNA drugs, and further chemical modifications are expected to improve the utility of siRNA therapeutics. As the 5' nucleobase of the guide strand affects the interaction between an siRNA and AGO2 and target cleavage activity, structural optimization of this specific position may be a useful strategy for improving siRNA activity. Here, using the in silico model of the complex between human AGO2 MID domain and nucleoside monophosphates, we screened and synthesized an original adenine-derived analog, 6-(3-(2-carboxyethyl)phenyl)purine (6-mCEPh-purine), that fits better than the natural nucleotide bases into the MID domain of AGO2. Introduction of the 6-mCEPh-purine analog at the 5'-end of the siRNA guide strand significantly enhanced target knockdown activity in both cultured cell lines and in vivo animal models. Our findings can help expand strategies for rationally optimizing siRNA activity via chemical modifications of nucleotide bases.
\end{abstract}

Keywords: siRNA; chemical modification; Argonaute; RISC; RNA silencing; drug delivery

\section{INTRODUCTION}

Small interfering RNAs (siRNAs) are a class of small RNAs $\sim 21 \mathrm{nt}$ in length that selectively cleave complementary target mRNAs and inhibit their gene expression, thereby inducing RNA interference (RNAi) (Kawamata and Tomari 2010). siRNAs can be utilized not only as functional biological research tools but also as therapeutic agents that target diseases previously deemed "undruggable" by traditional small molecules (Hannon and Rossi 2004). For instance, the RNAi drug Patisiran (Onpattro) was recently approved as the first RNAi agent for the treatment of transthyretin-mediated amyloidosis, a rare hereditary disease (Adams et al. 2018).

For the clinical use of siRNA as drugs, various chemical modifications, such as $2^{\prime}$-deoxy-2'-fluoro-uridine ( $\left.2^{\prime}-F \mathrm{U}\right)$, nucleoside phosphorothioates (PSOs), and 2'-O-methyl (2'-O-Me) RNA, have improved the safety, efficacy, and

Corresponding author: jun.saito.su@kyowakirin.com

Article is online at http://www.rnajournal.org/cgi/doi/10.1261/rna. 073783.119. bioavailability of siRNA drugs (Chiu and Rana 2003; Czauderna et al. 2003; Jackson et al. 2006; Setten et al. 2019). Indeed, both siRNA strands in Onpattro are partially modified using 2'-O-methylation to balance chemical stability, immune stimulation effect, and silencing activity (Adams et al. 2018). Since further chemical modifications are expected to improve the clinical utility of siRNA therapeutics, it is important to rationally design chemical modifications at specific positions based on the precise understanding of the molecular mechanism of RNAi.

The core component of the RNAi pathway is the RNaseH-like endonuclease Argonaute (AGO), which incorporates siRNAs and forms the effector complex RNAinduced silencing complex (RISC). AGO proteins are composed of N, PAZ, MID, and PIWI domains (Song et al.

(C) 2021 Shinohara et al. This article is distributed exclusively by the RNA Society for the first 12 months after the full-issue publication date (see http://rnajournal.cshlp.org/site/misc/terms.xhtml). After 12 months, it is available under a Creative Commons License (Attribution-NonCommercial 4.0 International), as described at http:// creativecommons.org/licenses/by-nc/4.0/. 
2004; Yuan et al. 2005; Wang et al. 2008). The monophosphate and nucleobase at the $5^{\prime}$-end of the guide strand of an siRNA duplex are anchored in the $5^{\prime}$ nucleotide-binding pocket at the interface between the MID and PIWI domains (Nakanishi et al. 2012; Schirle and MacRae 2012). Several studies have elucidated the functional importance of the $5^{\prime}$ nucleobase. For example, endogenous microRNAs (miRNAs) that associate with human AGO proteins show a stronger bias toward uracil or adenine compared with cytosine or guanine at their $5^{\prime}$-end ( $\mathrm{Hu}$ et al. 2009). Substituting the $5^{\prime}$ uracil of let-7 miRNA with other nucleotides compromised target cleavage activity of purified human AGO2 (Felice et al. 2009). Crystal structure and nuclear magnetic resonance (NMR) titration analyses of the isolated human AGO2 MID domain showed a strong binding preference for uracil or adenine through specific contacts at a rigid loop, termed the nucleotide specificity loop, in the MID domain (Frank et al. 2010). Crystal structure analysis of the full-length human AGO2 also confirmed the molecular basis for the $5^{\prime}$-end nucleobase preference (Schirle and MacRae 2012).

Given that the $5^{\prime}$ nucleobase of the guide strand affects the interaction between the siRNA and AGO2 and target cleavage activity, chemical modification of this specific position may be a useful strategy for improving siRNA activity. In theory, such modifications should have a compatible shape that can fit within the $5^{\prime}$-end binding pocket of the human AGO2 MID domain. Notably, metabolically stable $5^{\prime}$-(E)-vinylphosphonate (5'-E-VP), a $5^{\prime}$-phosphate modification, is known to increase not only the metabolic stability but also the binding affinity to $\mathrm{AGO} 2$, leading to in vitro and in vivo activity enhancements (Lima et al. 2012; Prakash et al. 2016; Coles et al. 2017; Haraszti et al. 2018). On the other hand, 5' nucleobase modifications for siRNA activity enhancement based on increasing the binding affinity to AGO2 have not been fully explored. Onizuka et al. (2013) performed structure-guided computational screening and identified a triazolyl nucleotide analog that performs well at the guide strand $5^{\prime}$-end. Interestingly, the triazolyl modification at the $5^{\prime}$-end of the guide strand markedly reduced the off-target silencing toward partially complementary targets, whereas on-target silencing toward a fully complementary target doubled.

Here, we aimed to improve the on-target activity of siRNAs by designing new nucleobase analogs that fit better than the natural nucleotides to the $5^{\prime}$-end nucleotidebinding pocket of human $\mathrm{AGO} 2$. By using the in silico model of the complex between human AGO2 MID domain and nucleoside monophosphates, we performed computational screening of purine nucleobase analogs that have the potential to create new interactions with the pocket. The screening identified several analogs that appeared to be accessible with a high affinity to the AGO2 MID 5' nucleotide-binding site. Moreover, there was a positive correlation between binding affinity to the
AGO2 MID 5' nucleotide-binding site and siRNA activity enhancement by $5^{\prime}$-end modification of the siRNAs.

\section{RESULTS}

\section{Identification of 8-Br AMP via in silico analysis and structure-guided seed optimization}

To obtain the purine analogs that bind with higher affinity than natural nucleotides to the AGO2 MID domain, a computational analysis was undertaken to characterize the 5 -end nucleotide-binding pocket and its surroundings based on the X-ray crystal structure of AMP-bound MID domain (PDB ID: 3LUD). The nucleotide-binding pocket was characterized by the positional preference of probe atoms, that is, hydrophobic and hydrogen-bond donor/acceptor atoms, on the grid prepared in and around the pocket. As shown in Figure 1, the results illustrate not only the complementarities between AMP and the nucleotide-binding pocket, but also the clues for structure-guided optimization of AMP to enhance binding affinity to AGO2. For example, the isosurfaces of the hydrogenbond donor/acceptor capture the oxygens in the phosphate group and uracil at the 5 '-end.

During analysis, spaces were found around the N6 and C8 of the adenine (Fig. 1; Supplemental Fig. 1). First, we explored the potential substituents to gain additional interactions with $\mathrm{AGO} 2$ via fragment-growing calculation for the $\mathrm{C} 8$ of the adenine. Candidate substituents were selected where a halogen at this position appeared to be favorable (Supplemental Table 2). Thus, 8-Br AMP was selected as a starting point, as it seemed to be better accommodated in the $5^{\prime}$ nucleotide-binding pocket (Supplemental Fig. 2) and was the only commercially available analog at the time of our study.

\section{A modified purine analog can fit into the $5^{\prime}$ binding pocket of AGO2}

To determine the exact mode of 8-Br AMP binding to the AGO2 MID domain, we followed previously reported methods to analyze the crystal structure of the AGO2 MID domain in complex with 8-Br AMP (Frank et al. 2010; Schirle et al. 2014). Protein atoms from the original AGO2 MID domain in complex with AMP (PDB ID: 3LUD) were used as the initial model of the complex. The root-mean-square deviation (RMSD) was $0.30 \AA$ for the nucleotides and $0.17 \AA$ overall (Fig. 2A).

The structure of the MID domain in complex with the 8-Br AMP was essentially the same as in the AMP complex state (PDB ID: 7D7U). The positions of the phosphorous and ribose atom in both complexes were identically aligned between the two structures (Fig. 2B). The AMP and 8-Br AMP bases stacked up against Y529, a crucial residue in the 5'-phosphate and nucleobase binding pocket 
A

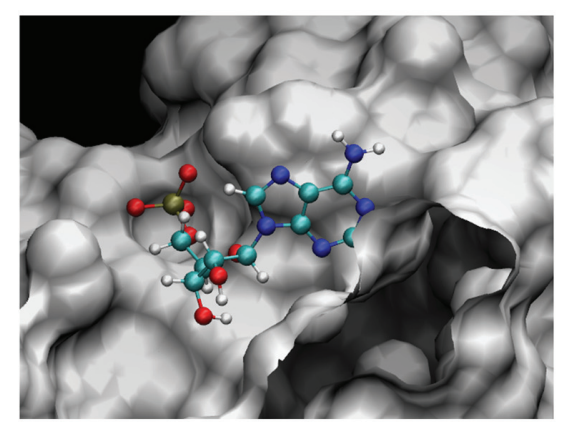

C

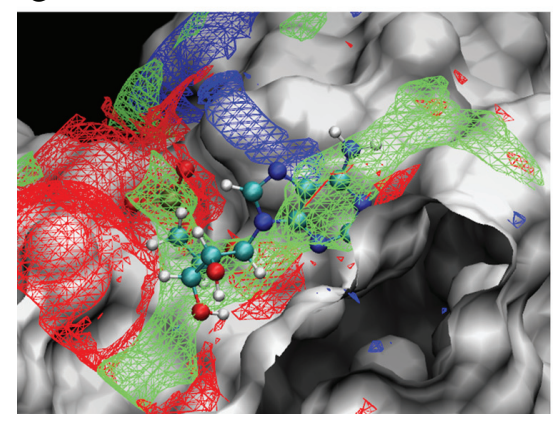

B

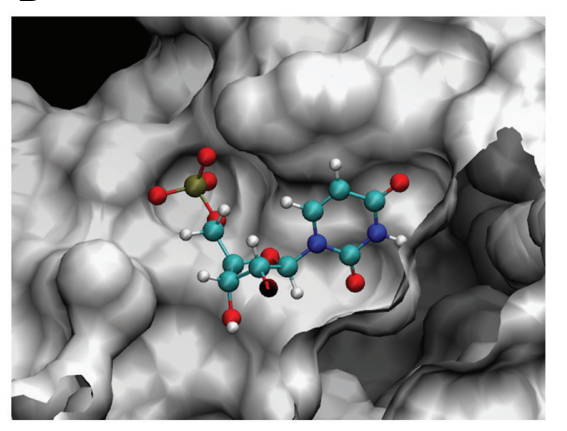

D

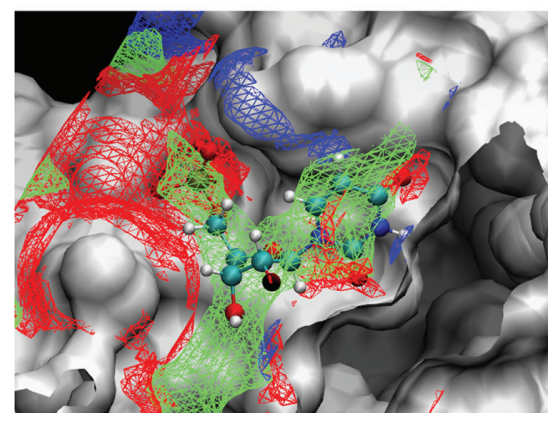

FIGURE 1. In silico high-probability isosurface analysis of the hydrogen bond acceptor (red mesh), hydrogen bond donor (blue mesh), and hydrophobic moiety (green mesh). (A) AMPbinding pocket. (B) UMP-binding pocket. (C) AMP-binding pocket shown with wireframes. (D) UMP-binding pocket shown with wireframes. To visualize the isosurfaces, a cut-off of $-1.5 \mathrm{kcal} / \mathrm{mol}$ was implemented for the interaction energy with AGO2. All calculations were performed in the apo form. AMP and UMP are shown to illustrate their respective binding sites in the pockets. AMP and UMP are represented as a ball-and-stick model (hydrogen, white; carbon, aqua; nitrogen, dark blue; oxygen, red; phosphorus, ocher). The molecular surface of AGO2 is shown in white. The figures were prepared using the molecular graphics program VMD (Humphrey et al. 1996).

that contributes to nonspecific recognition of the $5^{\prime}$ nucleotide in AGO2. However, in the 8-Br AMP complex structure, additional and specific hydrophobic interactions occurred between the bromine at the $\mathrm{C} 8$ of the adenine and Y529.

Next, we focused on the unoccupied space around the N6 of the adenine (Fig. 1). The environment around this position has been shown to be hydrophobic by in silico analysis, and the N6 amino group shows no significant interaction with the nucleotide-specific loop. Thus, we decided to replace the N6 amino with a phenyl group. In addition, given that in silico analysis indicated that the hydrophobic moiety may stretch further and a few hydrogenbond acceptor atoms may exist around the N6 of the adenine, we designed the 6-(3-(2-carboxyethyl)phenyl)purine (6-mCEPh-purine) analog with an acidic function for the phenyl group (Fig. 2C). Further details on the 6-mCEPhpurine monomer synthetic procedures are described in the Supplemental Materials and Methods.

The exact mode of 6-mCEPh-purine binding to the AGO2 MID domain was also examined, and the structure of the MID domain in complex with the 6-mCEPh-purine

analog was found to be essentially the same as in the AMP complex state (PDB ID: 7C6B). We confirmed that the interaction between the purine base portion, the ribose portion, and the 5'-phosphate group of 6-mCEPhpurine was the same as that in the Ago2-MID/AMP complex. Although the carboxyl group of the 3-(2-carboxyethyl) phenyl group at the N6 of the adenine was expected to acquire an ionic interaction with Lys525, the carboxyl group did not form a significant interaction with Lys525 but formed an interaction with the Thr526 backbone carbonyl via a water molecule (Fig. 2D). In ourcrystalstructureanalysis, only the anti-conformation was observed for the 8-Br AMP and 6-mCEPhpurine monomer. Although some substituents may have a syn conformation depending on their structure, we consider the anti-conformation to be more stable, as observed in the MID and 8-Br AMP or 6-mCEPhpurine monomer $\mathrm{X}$-ray structure.

\section{Purine analogs for modification of the 5 '-end of the guide strand increase affinity for the AGO2 MID domain}

Based on the interactions observed with the crystal structure of 8-Br AMP and 6-mCEPh-purine, we next sought to measure binding affinity to the AGO2 MID domain by ${ }^{1} \mathrm{H}^{15} \mathrm{~N}$ heteronuclear single quantum coherence $\left({ }^{1} \mathrm{H}-{ }^{15} \mathrm{~N} \mathrm{HSOC}\right) \mathrm{NMR}$ titration experiments, as previously described (Frank et al. 2010). First, chemical shift changes upon nucleotide titration were confirmed in the NMR spectrum. The titration experiment indicated that residues showing large chemical shift changes are located within the nucleotide-binding pocket, as seen in the crystal structures. Next, we compared the affinity of AMP, 8-Br AMP, and 6-mCEPh-purine for the AGO2 MID domain using the signals around the nucleotide-binding pocket. At least 16 signals, corresponding mainly to backbone amides, were used to determine the dissociation constant $\left(K_{d}\right)$ value from the binding curves generated by the titration of each nucleotide.

The $K_{d}$ value obtained for AMP was $380 \pm 9 \mu \mathrm{M}$ (Fig. 3A), which is consistent with that reported in a previous study $(\sim 280 \mu M)$ (Frank et al. 2010). Notably, 8-Br AMP showed a $K_{d}$ value of $100 \pm 4 \mu \mathrm{M}$ (Fig. 3B) for the AGO2 MID domain, suggesting that modification of bromine at the C8 of the adenine increases affinity by approximately 
A

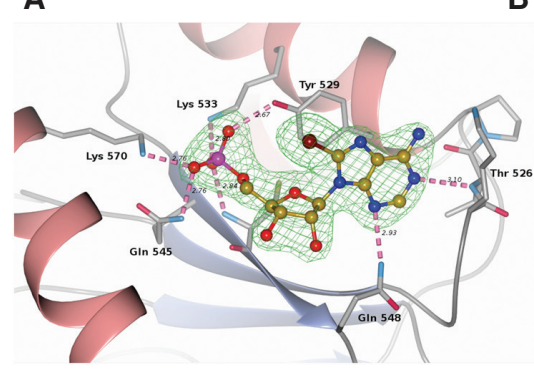

B

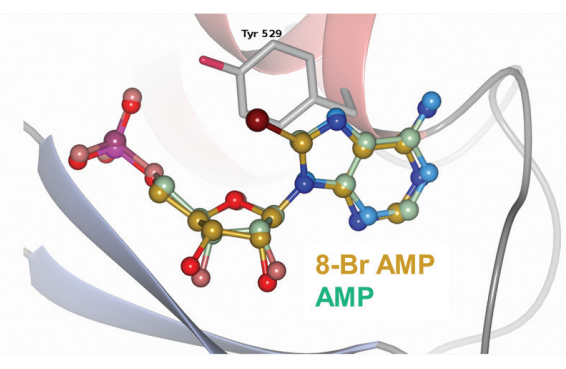

C

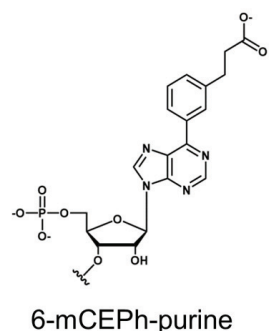

6-mCEPh-purine

FIGURE 2. Crystal structures of the complex between human AGO2 MID domain and modified nucleoside monophosphates. (A) 8-Br AMP electron density and its interactions with Ago2-MID (PDB ID: 7D7U). The 8-Br AMP molecule is shown as a ball-and-stick model with its carbon atoms in gold. The main chain structure of Ago2-MID is shown as a ribbon model, while the amino acid residues and water molecules incorporated in the interactions are shown as simple stick models and red balls, respectively. The hydrogen bonds are indicated by pink dashed lines, and the ligand-omitted $F_{o}-F_{c}$ electron density map at the $3.0 \sigma$ level is represented as a green mesh. (B) Superimposed AMP in the AGO2-MID/8-Br AMP complex. 8-Br AMP and AMP molecules are shown as ball-and-stick models with their carbon atoms in gold and pale green, respectively. The protein structure of the AGO2-MID/8-Br AMP complex is illustrated as a ribbon model. (C) Chemical structure of 6-mCEPh-purine. (D) 6-mCEPh-purine electron density and its interactions with AGO2-MID (PDB ID: 7C6B). 6-mCEPh-purine molecule is shown as a ball-and-stick model with its carbon atoms in moss green. The main chain structure of AGO2-MID is shown as a ribbon model, while the amino acid residues and water molecules incorporated in the interactions are represented as simple stick models and red balls, respectively. The hydrogen bonds are indicated by pink dashed lines, and the ligand-omitted $F_{o}-F_{c}$ electron density map at the $3.0 \sigma$ level is represented as a green mesh.

the effects of $5^{\prime}$-end substitutions were previously observed between natural bases. In agreement with known literature that siRNAs with $A$ or $U$ at the $5^{\prime}$-end of the guide strand have higher activity than those with a G or C (Amarzguioui and Prydz 2004; Reynolds et al. 2004; Ui-Tei et al. 2004), siRNAs with $A$ or $U$ at the $5^{\prime}$ end showed higher activity, and the activity of siRNAs with $A$ and $U$ was not significantly different (Supplemental Fig. 3). Next, siRNA duplexes targeting luciferase with 5' 6-mCEPhpurine were also synthesized, after which RNAi activity of siRNA with $5^{\prime}$ 6-mCEPh-purine on the guide strands was investigated. Details regarding the 6-mCEPh-purine-loaded oligonucleotide synthetic procedures are described in the Supplemental Materials and Methods. We found that replacement of the adenine base at the 5 '-end of siRNA guide strands with 6$\mathrm{mCEPh}$-purine was well-tolerated and resulted in a 2.4- to 2.9-fold higher potency than that of the $5^{\prime} A$ luciferase-targeting siRNAs (Fig. 4A,B).

To further assess the effect of 5' 6-mCEPh-purine on the AGO2siRNA interaction, we analyzed the amount of $5^{\prime}$ 6-mCEPh-purine-modified siRNA bound to AGO2 by immunoprecipitation. HeLa cells were transfected with 5' 6-mCEPh-purine or 5' A luciferase-targeting siRNAs.

fourfold compared with that of AMP. The $K_{d}$ of the 6mCEPh-purine analog to the AGO2 MID domain was also determined from the binding curves by plotting the titration of the 6-mCEPh-purine monomer (Fig. 3C), which was found to be $42 \pm 4 \mu \mathrm{M}$; thus, compared with AMP, the 6-mCEPh-purine analog had an approximately ninefold higher affinity. Because the affinity of the 6-mCEPhpurine was found to be stronger than that of $8-\mathrm{Br} A M P$, 6-mCEPh-purine-modified siRNA was synthesized and evaluated in a subsequent knockdown experiment.

\section{The 5' AMP-derived modification is more potent than its $5^{\prime}$ AMP counterparts at the $5^{\prime}$-end of the guide strand}

We evaluated the effect of the nucleobase 6-mCEPh-purine modification at the $5^{\prime}$-end of the siRNA guide strands. To determine the effect of 6-mCEPh-purine at this position, siRNA duplexes targeting luciferase were designed, and
Subsequently, AGO2 protein was immunoprecipitated from cell lysates after $24 \mathrm{~h}$, and the amount of coimmunoprecipitated single guide strands was determined by qRTPCR. As shown in Figure 4C, each of the siRNAs was loaded on RISC. The 5' 6-mCEPh-purine siRNA guide strand was present at 1.9-fold in $5 \mathrm{pM}$ and 2.4-fold in $50 \mathrm{pM}$ higher levels than those of $5^{\prime}$ A siRNAs. The enhanced RISC uptake by the $5^{\prime}$ 6-mCEPh-purine modification was also observed in other siRNA sequences (Supplemental Fig. 4). Additionally, the time-course of Ago2-associated guide strand copy number of 5'-A and 5'-6-mCEPh-purine siRNA determined 1, 2, and $3 \mathrm{~d}$ after $50 \mathrm{pM}$ siRNA treatment and the enhanced RISC uptake by the 5' 6-mCEPh-purine modification were observed at each time point (Fig. 4D).

These findings demonstrate a correlation between RISC loading and siRNA potency, suggesting that the $5^{\prime}$ 6-mCEPh-purine-modified siRNAs were efficiently recognized by AGO2 and that AGO2-bound siRNAs are present for a longer duration in cell culture. 
A

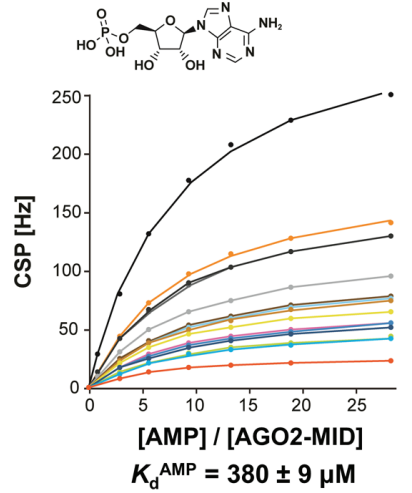

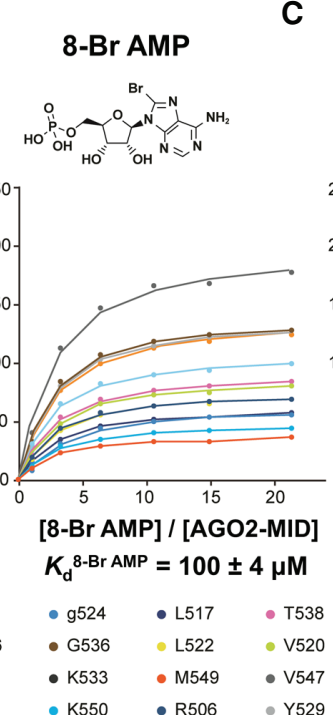

$\begin{array}{llll}\bullet \text { x200 } & \bullet \text { g524 } & \bullet \text { L517 } & \bullet \text { T538 } \\ \text { - C546 } & \bullet \text { G536 } & \bullet \text { L522 } & \bullet \text { V520 } \\ \text { - E531 } & \bullet \text { K533 } & \bullet \text { M549 } & \bullet \text { V547 } \\ \text { - F505 } & \bullet \text { K550 } & \bullet \text { R506 } & \bullet \text { Y529 }\end{array}$

\section{6-mCEPh-purine}
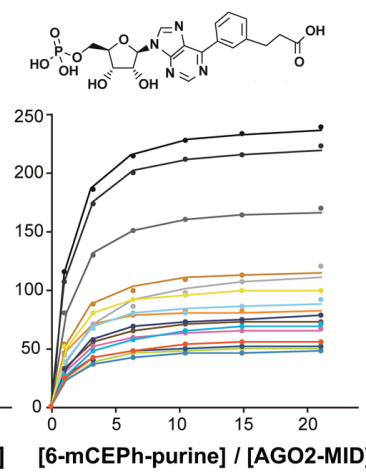

$K_{\mathrm{d}}{ }^{6-m C E P h-p u r i n e}=42 \pm 4 \mu \mathrm{M}$

FIGURE 3. Simultaneous fitting for determination of the dissociation constant. Chemical shift upon nucleotide titration of (A) AMP, (B) 8-Br AMP, and (C) 6-mCEPh-purine. Profiles of backbone ${ }^{1} \mathrm{HN} /{ }^{15} \mathrm{~N}$ chemical shift differences $\left(\Delta_{\mathrm{H} / \mathrm{N}}\right)$. For the determination of $K_{\mathrm{d}}$, the following signals were selected, (1) isolated from other signals in each titration and (2) CSP $>20 \mathrm{~Hz}$ (shown). Sixteen signals were used for simultaneous fitting (right edge, $\times 200$ means unassigned signal; single letters represent the amino acid).

\section{5' 6-mCEPh-purine ApoB-targeting siRNA reduces ApoB levels in cell culture and in vivo}

To evaluate whether the 5' 6-mCEPh-purine siRNA exhibits higher potency than siRNAs with a natural nucleotide toward an endogenous gene, 5' 6-mCEPh-purine apolipoprotein $B(A p o B)$-targeting siRNA was synthesized, and its activity first confirmed in a cell culture assay. To ensure the feasibility of the modification at the N6 of the adenine and the importance of the negatively charged side chain, we additionally synthesized a 6-(Phosphonooxy-Butyl-Sulfide)Purine (6-PBuS-purine) analog that has a 4-phosphonooxybutylthio group acidic side chain at the N6 of the adenine (Fig. 5A). Activities of the 5' 6-mCEPh-purine and 6-PBuS-purine siRNAs were similar to each other and fourfold to sixfold greater than that of $5^{\prime} \mathrm{A}$ siRNA (Fig. 5B,C).

Next, lipid nanoparticle (LNP)-formulated 5' 6-mCEPhpurine and 6-PBuS-purine ApoB-targeting siRNAs were evaluated for target gene silencing in vivo. Mice were treated with a single intravenous dose of $0.03-0.3 \mathrm{mg}$ siRNA $/ \mathrm{kg}$, after which we observed reduced $A p o B$ mRNA levels in the liver $2 \mathrm{~d}$ and $7 \mathrm{~d}$ after administration. At $2 \mathrm{~d}$ post-treatment with $0.1 \mathrm{mg}$ siRNA $/ \mathrm{kg}$, the $5^{\prime}$ 6mCEPh-purine and 6-PBuS-purine ApoB-targeting siRNA reduced liver $A$ poB mRNA levels by $~ 80 \%$ compared with that of saline-treated mice, whereas the $5^{\prime} A$ ApoB-targeting siRNA reduced ApoB levels by only $50 \%$. Moreover, since the persistence of ApoB mRNA knockdown level by 5' 6-mCEPh-purine and 5' 6-PBuS-purine

siRNAs exceeded that of $5^{\prime} A$ siRNA on day 7 , it was also suggested that 5' 6-mCEPh-purine and 6-PBuS-purine $A p o B$ prolong the knockdown effect (Fig. 6A-C).

To further investigate the effect of the 5' 6-mCEPh-purine and 6-PBuSpurine modifications, changes in total plasma cholesterol levels following ApoB mRNA knockdown were investigated in BALB/c mice on day 7 after treatment. Plasma cholesterol levels decreased in a dose-dependent manner. Moreover, consistent with the enhanced reduction in ApoB mRNA levels, this reduction in plasma cholesterol levels was also enhanced by the $5^{\prime}$ 6-mCEPh-purine and 6-PBuSpurine siRNAs (Fig. 6D).

\section{DISCUSSION}

siRNAs have revolutionized the field of drug discovery and development and made it possible to decrease the levels of disease-causing proteins. Most siRNAs that are currently in clinical use and/or testing are chemically modified to optimize biological activity and therapeutic application (Deleavey and Damha 2012). Although the complex interactions between AGO2 and an siRNA duplex complicate chemical modification approaches, $5^{\prime}$ terminal modifications have been established as a rational strategy for modulating siRNA activity (Onizuka et al. 2013; Suter et al. 2016; Zlatev et al. 2016; Elkayam et al. 2017).

In this study, we developed a structure-guided screening strategy to discover functional 5 '-end modifications that can enhance the siRNA-AGO2 interaction by using in silico screening, NMR-binding assay, and X-ray structural analysis. We found that the N6 and $\mathrm{C} 8$ of the adenine at the $5^{\prime}$-end guide RNA have potential for structural optimization (Figs. 1, 2); compared with AMP, the 6-mCEPhpurine modification exhibited an approximately ninefold higher binding affinity to the AGO2 MID domain (Fig. 3), and siRNA with a substituted N6 adenine showed threeto sixfold higher siRNA activity than that of natural base adenine in cell culture and in vivo (Figs. 4-6). We also found that the amount of assembled AGO2-RISC increased by the 6-mCEPh-purine modification (Fig. 4). Given that siRNA incorporation into AGO2 leads to RISC stabilization (Yoda et al. 2010), sustained siRNA activity in our mouse model at day 7 would result from 6-mCEPh-purine modification-induced siRNA accumulation in RISC. Consistent with these observations, in an accompanying manuscript (Brechin et al. 2021), a series of biochemical approaches were used that demonstrated that the 6-mCEPh-purine 
A

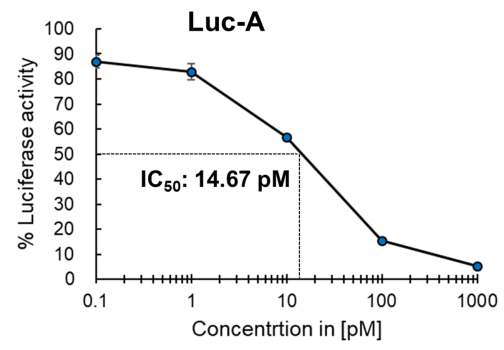

B

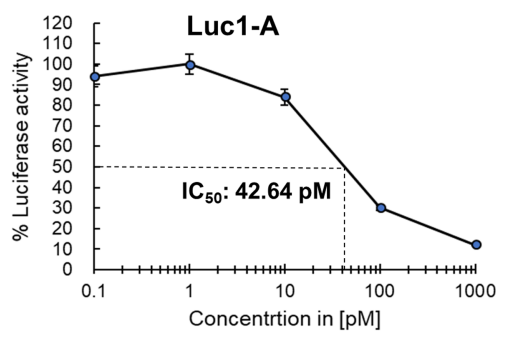

C

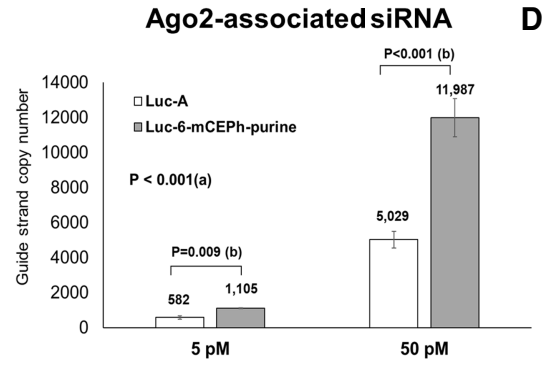

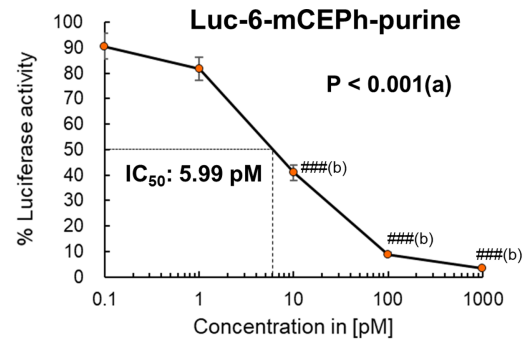

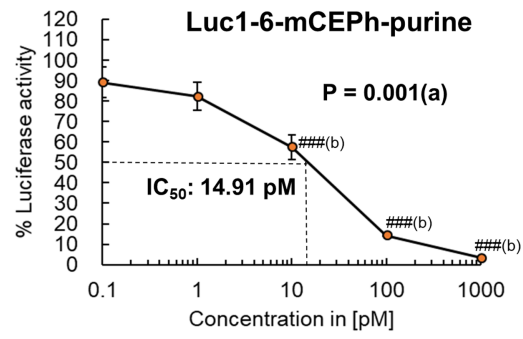

D

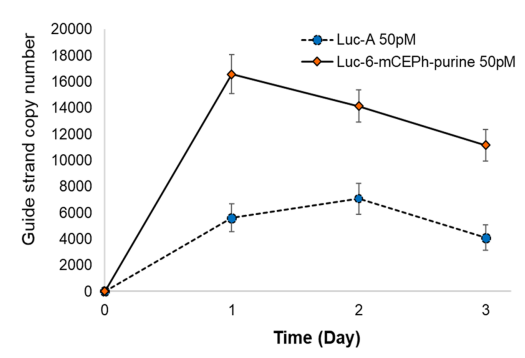

FIGURE 4. The 6-mCEPh-purine modification enhances siRNA activity. (A) Luc sequence. (B) Luc1 sequence. Comparison of RNAi activity of luciferase-targeting siRNAs, each bearing A or 6-mCEPh-purine at the $5^{\prime}$-end of the guide strand. Relative levels of luciferase luminescence in luciferase-expressing HeLa cells after treatment with various concentrations of transfected siRNA. Data are represented as the means $\pm \mathrm{SD}, n=5$, The 6-mCEPh-purine $P$ value was calculated by comparison with 5'-A. P-value (a) Two-way ANOVA, ${ }^{\# \# \#) ~} P<0.001$ (b): unpaired t-test. (C) Ago2-associated guide strand copy number of 5'-A and 5'-6-mCEPh-purine siRNAs. The amount of RISC-loaded guide strand was determined by immunoprecipitation of AGO2 from HeLa cells and qRT-PCR. siRNAs were transfected into cells at concentrations of $5 \mathrm{pM}$ and $50 \mathrm{pM}$. Copies of guide strands were calculated per cell lysate. Data are represented as the means $\pm S D, n=3$. The 6 -mCEPh-purine $P$ value was calculated by comparison with

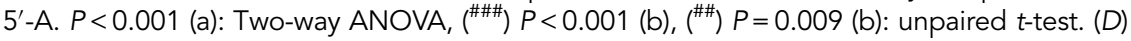
Time-course of Ago2-associated guide strand copy number. Ago2-associated guide strand copy number of 5'-A and 5'-6-mCEPh-purine siRNA was determined at 1, 2, and $3 \mathrm{~d}$ after $50 \mathrm{pM}$ siRNA treatment. Data are represented as the means $\pm S D, n=6$.

modification improves the assembly of AGO2-RISC by at least two different mechanisms. The explanation also suggests that the effect of 6-mCEPh-purine modification is exerted at the stage of mature Ago2-RISC formation rather than by affecting the efficiency of pre-Ago2-RISC formation, as discussed by Brechin et al. (2021).

It has been previously reported that purine derivatives with size-expanded substituents (Onizuka et al. 2013) and 2-aminopurine N2 substituents (Felice et al. 2009) are not tolerated at the $5^{\prime}$-end of the guide strand, presumably because these analogs do not fit the $5^{\prime}$-nucleotidebinding pocket of the AGO2 MID domain (Frank et al.
2010). In this report, we obtained the first purine derivative analogs that show a higher on-target knockdown activity than that of the natural nucleotides by adding a new side chain at the $\mathrm{N} 6$ of the adenine while conserving the original interactions between AMP and the 5'-nucleotide-binding pocket. Regarding the C8 position, 8-Br AMP was found to fit the $5^{\prime}$-end binding site on the MID domain and stacked up against Y529; thus, we can assume that the PIWI domain has almost no effect on $\mathrm{C} 8$ recognition. On the other hand, we cannot exclude the involvement or interaction of PIWI (R814, Y815) with the C6 position based on the analysis of the siRNA-human AGO2 structure. However, considering that the binding affinity between 6-mCEPh-purine and MID was enhanced (Fig. 3), the 6-mCEPh-purine appears to interact primarily with the MID domain.

As AGO2 associates with the guide strand not only via the $5^{\prime}$ nucleotidebinding pocket but also through many other internal interactions, further enhancement of the binding affinity at the $5^{\prime}$-end is likely required for additional improvement of the overall knockdown activity. One possible approach is to include the modification at the $\mathrm{C} 8$ of the adenine at the $5^{\prime}$-end guide RNA, considering that the bromine in this position showed an additional hydrophobic interaction with Y529 in our analysis (Fig. 2A). A combination of modifications at the $\mathrm{N} 6$ and $\mathrm{C} 8$ of the adenine may be another strategy to significantly improve the affinity of the $5^{\prime}$ end. Of note, it has been suggested that AGO2 is also compatible with $5^{\prime}$-phosphate mimics, such as $5^{\prime}$-(E)-vinylphosphonate (5'-E-VP). Compared with the natural $5^{\prime}$-phosphate, metabolically stable $5^{\prime}$-E-VP modification can lead to in vivo stability, increased RISC assembly, and higher gene silencing activity of modified siRNAs (Zlatev et al. 2016; Elkayam et al. 2017). Therefore, combining such 5 '-phosphate mimics and our 5 '-nucleobase modifications represents another strategy for achieving increased knockdown efficiency and durability. Nevertheless, the detailed complex structure and complex functions between heavily chemically modified siRNA and $\mathrm{AGO} 2$ are not yet fully understood. Therefore, based 
A

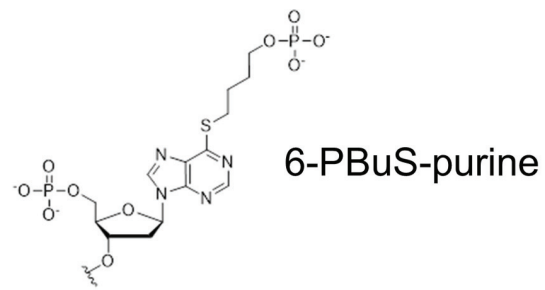

B

Luc9-A

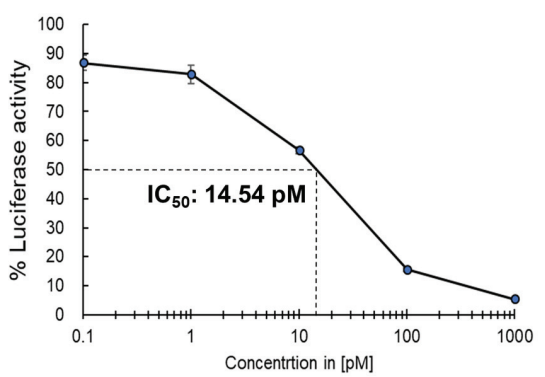

C

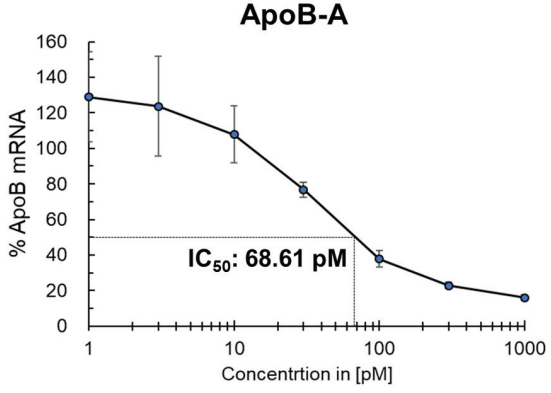

Luc9-6-mCEPh-purine

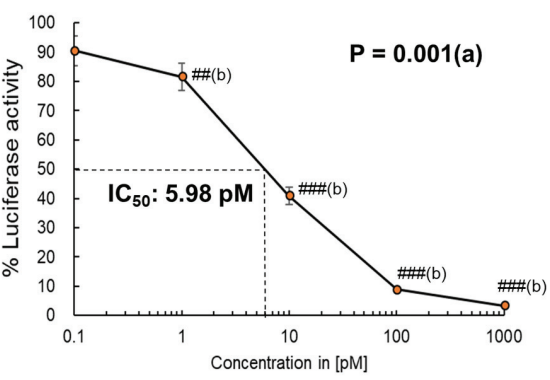

ApoB-6-mCEPh-purine

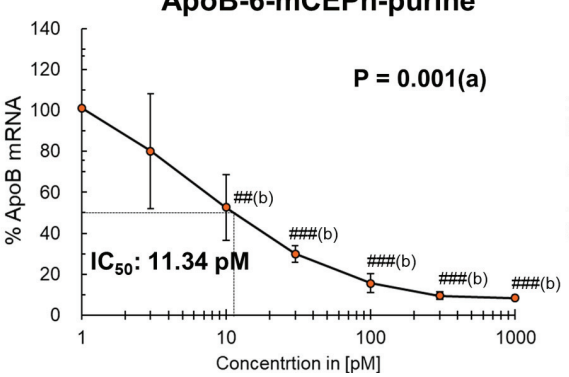

Luc9-6-PBus-purine
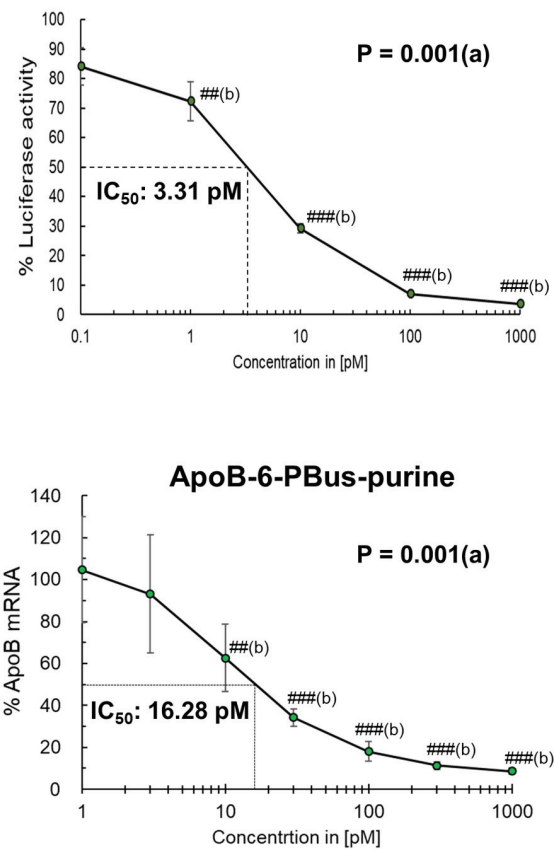

FIGURE 5. siRNA activity of $5^{\prime}-A, 5$ - -6 -mCEPh-purine, and 5'-6-PBuS-purine siRNAs (A) Chemical structure of 6-PBuS-purine. (B) Comparison of RNAi activity of luciferase-targeting siRNAs, each bearing A, 6-mCEPh-purine or 5'-6-PBuS-purine at the $5^{\prime}$-end of the guide strand. Relative levels of luciferase luminescence in luciferase-expressing HeLa cells after treatment with various concentrations of transfected siRNA. Data are represented as the means $\pm \mathrm{SD}, n=5$. The 6-mCEPh-purine $P$-value was calculated by comparison with $5^{\prime}-\mathrm{A}$. $P$-value (a) Two-way ANOVA, $\left({ }^{\#}\right) P<0.05$

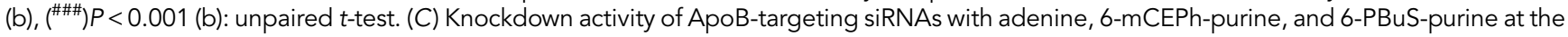
guide strand 5 -end. Relative levels of $A p o B$ mRNA in mouse primary cells after treatment with various concentrations of transfected siRNA. Data are represented as the means $\pm S D, n=5 ; P=0.001$ (a): two-way ANOVA; $\left({ }^{\# \#)} P<0.05(b),(\# \#) P<0.001(b)\right.$ : one-way ANOVA; $(*) P<0.05,\left({ }^{* *}\right) P<$ 0.01: unpaired t-test and Bonferroni correction.

on newly discovered structural analysis results, a combination of local and global siRNA structure optimization-taking into account the complex and stepwise interactions between AGO2 and heavily chemically modified siRNA - can be effective for further improvement of siRNA therapeutics.

\section{MATERIALS AND METHODS}

\section{Computational methods}

X-ray crystal structures of AMP- or UMP-bound AGO2 MID domain were obtained from the Protein Data Bank (PDB ID: 3LUD, 3LUJ). The following procedures were performed in Molecular Operating Environment (MOE; 2010.10; Chemical Com- puting Group ULC). Missing atoms and residues were restored, and hydrogen atoms were added using the Protonate3D module. Atomic partial charge was assigned based on the MMFF94 $\times$ force field, and each structure was energetically minimized. To characterize the $5^{\prime}$-end nucleotide-binding pocket and its surrounding, the AMP- or UMP-unbound apo form of AGO2 was prepared by the removal of AMP/UMP and water molecules from each complex. The grids were then generated with an interval of $0.4 \AA$ in and around the AMP/UMP binding pocket. Each of the hypothetical atoms, such as hydrophobic or hydrogen bond acceptor/ donor atoms, was placed on the grid point to evaluate the interaction energy with AGO2. The results can be used for the identification of the seed compound as well as for further structureguided seed optimization. In addition, a fragment-growing calculation was performed from when AMP/UMP had an empty space for introducing substituents using the combinatorial builder module, while the AGO2 and AMP/UMP structures remained fixed. 
A

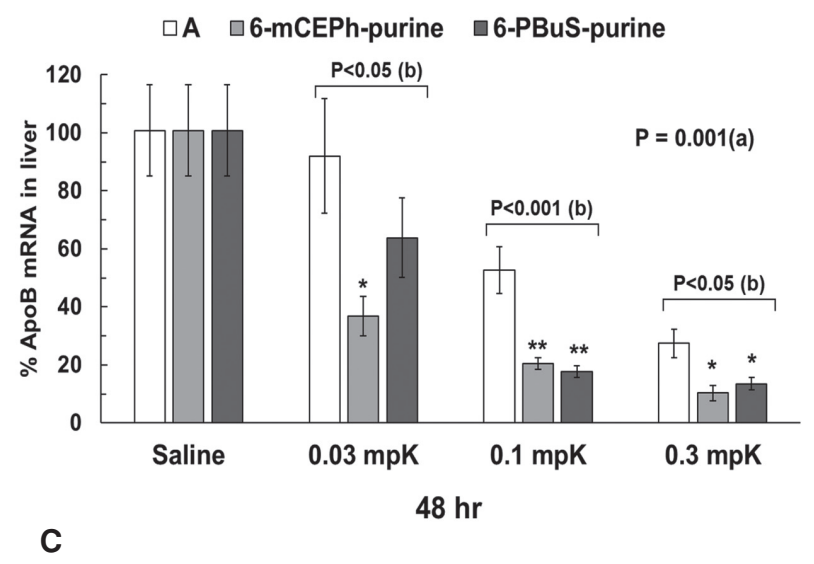

$\mathrm{IC}_{50}$ Values for each 5'-modification in ApoB mRNA Silencing in vivo assay

\begin{tabular}{ccc}
\hline \multirow{2}{*}{ 5'-modification } & \multicolumn{2}{c}{$\mathrm{IC}_{50}$ (mpk) } \\
\cline { 2 - 3 } & 48hr (Fig 4A) & 168hr (Fig 4B) \\
\hline A & 0.109 & $>0.3$ \\
6-mCEPh-purine & $<0.03$ & 0.073 \\
6-PBuS-purine & 0.043 & 0.181 \\
\hline
\end{tabular}

B

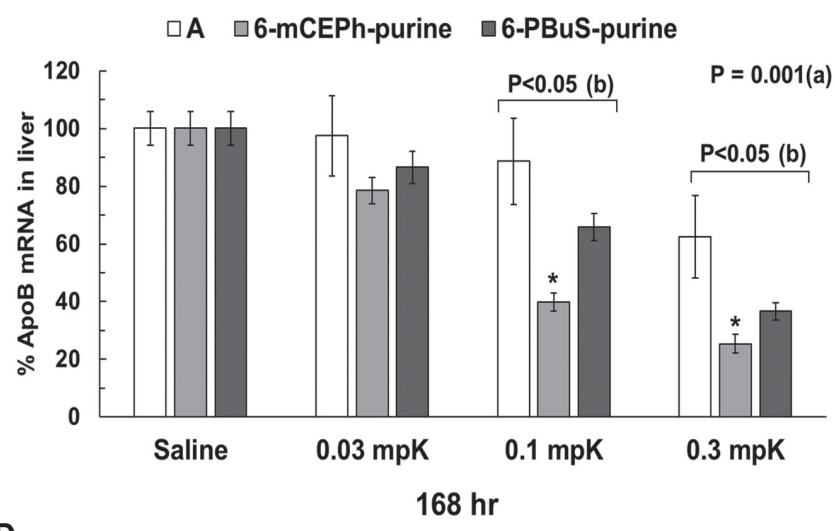

D

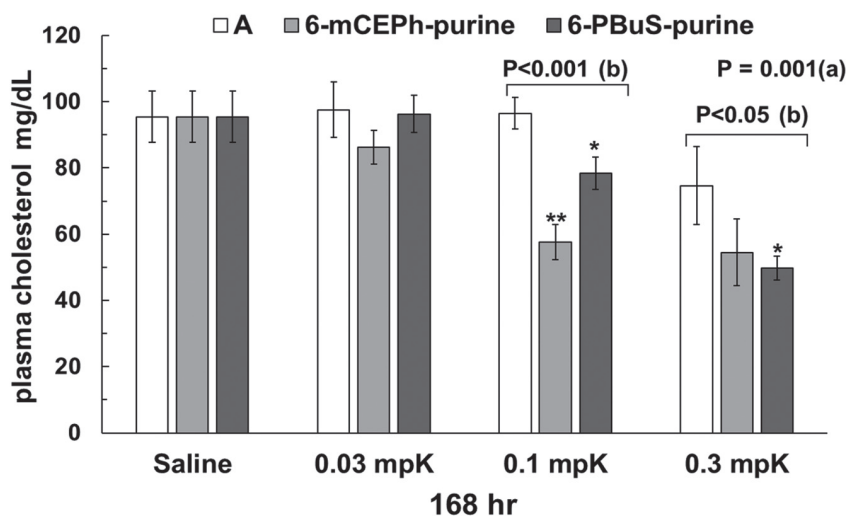

FIGURE 6. Knockdown activity of ApoB-targeting siRNAs in mouse liver at $48 \mathrm{~h}(\mathrm{~A})$ and $168 \mathrm{~h}(\mathrm{~B})$ with adenine, 6-mCEPh-purine, or 6-PBuS-purine at the $5^{\prime}$-end of the guide strand. $(C) I C_{50}$ values (mpk) obtained when mice were treated with $5^{\prime}$ modified siRNAs, determined after $48 \mathrm{~h}(A)$ and $168 \mathrm{~h} \mathrm{(B)} \mathrm{of} \mathrm{administration.} \mathrm{(D)} \mathrm{Total} \mathrm{cholesterol} \mathrm{in} \mathrm{mouse} \mathrm{plasma} \mathrm{after} \mathrm{the} \mathrm{administration} \mathrm{of} \mathrm{various} \mathrm{concentrations} \mathrm{of} \mathrm{LNP/siRNA.} \mathrm{Data} \mathrm{are} \mathrm{rep-}$ resented as the means $\pm \mathrm{SD}, n=3 . P=0.001$ (a): Two-way ANOVA, (b): One-way ANOVA, $\left(^{*}\right) P<0.05,\left(^{* *}\right) P<0.01$ : unpaired $t$-test_Bonferroni correction.

\section{AGO2 8-Br AMP and AGO2 6-mCEPh-purine complex structure determination}

RNA-free AGO2 MID domain was expressed and purified as previously described (Frank et al. 2010). The protein was then mixed with 8-Br AMP or 6-mCEPh-purine at a ratio of 1:2, after which the complex was purified and crystallized as previously described (Frank et al. 2010). X-ray diffraction data were collected at beamline NW12A of the Photon Factory-Advanced Ring (PF-AR) at the High Energy Accelerator Research Organization Institute of Materials Structure Science. Diffraction data were indexed, integrated, and scaled using the HKL2000 program (HKL Research, Inc.) or Mosflm (Leslie 2006). The structure was solved by molecular replacement using the protein chain of the AGO2 MID/AMP structure as a search model (PDB 3LUD) using MOLREP 5 in the CCP4 package (Vagin and Teplyakov 1997).

\section{NMR experiments}

All NMR experiments were performed at $20^{\circ} \mathrm{C}$ on Bruker AVANCE600 spectrometers (Bruker) equipped with z-gradient triple-resonance cryoprobes. The protein fragment of the
AGO2 MID domain was purified as previously reported (Frank et al. 2010) and dissolved in $25 \mathrm{mM}$ sodium phosphate, 150 $\mathrm{mM}$ sodium chloride, and $2 \mathrm{mM}$ tris(2-carboxyethyl)phosphine at a $\mathrm{pH}$ of 6.70. For $K_{\mathrm{d}}$ determination, $\mathrm{AMP}, 8-\mathrm{Br} \mathrm{AMP}$, or 6-mCEPh-purine monomer $(0-1.3 \mathrm{mM})$ was added to an $\left\{{ }^{15} \mathrm{~N}\right\}$-labeled AGO2 MID domain $(47 \mu \mathrm{M})$. $K_{d}$ was calculated from the titration data using selected residues, which show chemical shift perturbations upon AMP, 8-Br AMP, or 6-mCEPh-purine titrations.

\section{RNAi activity of luciferase-targeting siRNA}

HeLa cells (CCL-2; American Type Culture Collection [ATCC]) were transfected with pGL4.50 [luc2/CMV/Hygro] (Promega) vector and selected in hygromycin-containing RPMI medium (A10491 Gibco; Thermo Fisher Scientific). Luciferase-expressing HeLa cells were suspended in RPMI medium supplemented with $10 \%$ fetal bovine serum and seeded at $7.5 \times 10^{3}$ cells per well in 96-well culture dishes. Cells were transfected with siRNA using Lipofectamine RNAiMAX (13778-075; Invitrogen) in OPTIMEM (31985-070; Invitrogen) at $10 \mu \mathrm{L} /$ well, after which the cells were cultured at $37^{\circ} \mathrm{C}$ and $5 \% \mathrm{CO}_{2}$ for $24 \mathrm{~h}$. 
After culture, the Steady-Glo Luciferase Assay System (E2520; Promega) was added to each well according to the manufacturer's instructions. After the cells were incubated for $1 \mathrm{~min}$, the amount of luminescence (counts per second) in each well was measured using ARVO-X3 (PerkinElmer) according to the manufacturer's instructions. The relative RNAi effect on siRNA-transfected samples was expressed as the ratio of luminescence to that of the negative control group (non-siRNA transfected). Three individual assays were averaged to obtain the values and standard deviations plotted in the figures.

\section{Gene silencing experiments in cell culture}

For transfection into primary mouse hepatocytes, primary hepatocyte cells (MSCP10; Mouse [CD-1] Cryopreserved Hepatocytes, Pateable Male; Thermo Fisher Scientific) were suspended in plating medium consisting of Williams medium (A1217601; Life Technologies) supplemented with Hepatocyte Plating Supplement Pack (serum-containing; CM3000; Life Technologies) and seeded at $7.5 \times 10^{3}$ cells per well in 96-well plates. Cells were transfected with siRNA using Lipofectamine RNAiMAX according to manufacturer's instructions and cultured at $37^{\circ} \mathrm{C}$ and $5 \% \mathrm{CO}_{2}$ for $24 \mathrm{~h}$ prior to RNA isolation. To collect RNA and synthesize cDNA, total RNA was extracted and converted to cDNA using SuperPrep Cell Lysis \& RT Kit for qPCR (SCQ-101; Toyobo) according to the manufacturer's instructions. ApoB mRNA levels were quantified using the ApoB TaqMan probe (Mm01545156_m1; Thermo Fisher Scientific) and the HPRT TaqMan probes MmHPRT1_P6-mCEPh-purine (5'-TGGTTAAGGTTGCAAGCTTGCTGGTG-3'; Thermo Fisher Scientific), MmHPRT1_F576 (5'-CAAACTTTGCTTTCCCTGGT-3'; Sigma-Aldrich), and MmHPRT1_R664 (5'-CAACAAAGTCTGGCC TGTATC-3'; Sigma-Aldrich) on a QuantStudio12K Flex Real-Time PCR System (Applied Biosystems). Relative ApoB mRNA levels were normalized to HPRT MRNA and represented as the ratio of ApoB mRNA in siRNA-transfected samples to that of the negative control group (non-siRNA transfected).

\section{Preparation of LNPs}

Cationic lipid SST-02 [(3-hydroxylpropyl)dilinoleylamine] (Kuboyama et al. 2019) was synthesized in-house. PEG2000-DMPE [N-(carbonyl-methoxypolyethyleneglycol 2000)-1,2-dimyristoylsn-glycero-3-phosphoethanolamine; sodium salt], DSPC (1,2-distearoyl-sn-glycero-3-phosphocholine), and cholesterol were purchased from NOF. Each ApoB siRNA was encapsulated in LNP with a lipid composition of cationic lipid:PEG2000-DMPE: DSPC:cholesterol of 47.8:5.1:13.9:33.2 molar percent as described previously (Yamauchi et al. 2006; Yagi et al. 2009).

\section{In vivo mouse experiments}

All animal study procedures conducted at Kyowa Kirin were performed in accordance with the Standards for Proper Conduct of Animal Experiments at Kyowa Kirin Co., Ltd. under the approval of the company's Institutional Animal Care and Use Committee. Kyowa Kirin Co., Ltd. is fully accredited by the Association for the Assessment and Accreditation of Laboratory Animal Care, International.
In vivo efficacy studies were conducted on 5-wk-old Balb/cA male mice obtained from CLEA Japan, Inc. Mice were maintained on a constant 12-h light/12-h dark cycle in a temperature- and humidity-controlled room and provided food and water ad libitum. Mice were divided into three groups: adenine, 6-mCEPh-purine, and 6-PBuS-purine ( $n=3$ /group) and intravenously administered $0.03,0.1$, or $0.3 \mathrm{mg} / \mathrm{kg}$ LNP-encapsulated siRNAs via tail vein injections and euthanized at different time points following treatment. Blood and liver samples were collected on either day 2 or day 7 post-treatment (three mice for each time point).

Total RNA was isolated from liver tissue using the Cellular RNA Large Volume Kit (MagNA PURE 96; Roche) according to manufacturer's instructions. First strand cDNA was generated from $0.5 \mu \mathrm{g}$ total RNA using the Transcriptor Reverse Transcriptase and oligo (dT) primers included in the Transcriptor First Strand cDNA Synthesis Kit (04897030001; Roche). Taqman qPCR analysis was performed on the QuantStudio12K Flex system, as described above. mRNA knockdown activity was calculated relative to the saline-treated control in each experiment. Total cholesterol in mouse plasma was measured using the LabAssay Cholesterol Kit (Cat \# 294-65801; Wako Chemicals) according to manufacturer's instructions. Three individual assays were averaged to obtain the values and standard deviations plotted in the figures.

\section{Quantification of AGO2-associated siRNA levels}

Luciferase-expressing HeLa cells were suspended in RPMI medium supplemented with $10 \%$ fetal bovine serum and seeded at $1 \times 10^{4}$ cells per well in 96-well culture dishes. Cells were transfected with siRNA using Lipofectamine RNAiMAX in OPTI-MEM at $10 \mu \mathrm{L} /$ well, after which the cells were cultured at $37^{\circ} \mathrm{C}$ and $5 \% \mathrm{CO}_{2}$ for $24 \mathrm{~h}$. HeLa cells were collected $24 \mathrm{~h}$ post-treatment and lysed in $100 \mu \mathrm{L}$ lysis buffer M (034-21143; Wako Chemicals) and 1\% Protease Inhibitor Cocktail (P8340; Sigma-Aldrich). siRNA-containing supernatants were transferred to new tubes, after which siRNA guide strand levels were quantified by stem-loop reverse transcription followed by TaqMan qPCR.

Anti-AGO2 antibody was purchased from Wako Chemicals (clone no. 2D4). Dynabeads M-270 Epoxy (Life Technologies) was used to precipitate the antibodies. AGO2-associated siRNAs were eluted by adding $20 \mu \mathrm{L}$ lysis solution included in the TaqMan Gene Expression Cells-to-CT Kit (Invitrogen) for $10 \mathrm{~min}$. The reaction was stopped by adding $2 \mu \mathrm{L}$ of stop solution from the Cells-to-CT kit and quantified by qPCR.

The primers and TaqMan probe used for qPCR were synthesized by Sigma-Aldrich and Thermo Fisher Scientific, respectively. Extracted RNA and standard RNA were converted to cDNA using the TaqMan MicroRNA RT Kit (4366597; Thermo Fisher Scientific) according to manufacturer's instructions with the following primer: 5'-GTCGTATCCAGTGCAGGGTCCGAGGTATTCGCACTGG ATACGACATGGAT-3' for LUc， 5'-GTCGTATCCAGTGCAGGG TCCGAGGTATTCGCACTGGATACGACCACCGT-3' for Luc ex1, 5'-GTCGTATCCAGTGCAGGGTCCGAGGTATTCGCACTGGATA CGACCCGG-3' for Luc ex2. qPCR was performed using the TaqMan Gene Expression Master Mix (Thermo Fisher Scientific, 4369542), with the following primers: forward, 5'-TAGTCGGT CTTGCTATC-3' for Luc, 5'-TGCTCACGAATACGACGG-3' for Luc ex1, 5'-TGATCAGGCTCTTCAGCC-3' for Luc ex2; reverse, 
5'-GTGCAGGGTCCGAGGT-3' as a common primer to all sequences; and TaqMan probe, 5'-CTGGATACGACATGGA-3' for Luc, 5'-CTGGATACGACCACCG-3' for Luc ex1, 5'-CTGGATA CGACCCGGC-3' for Luc ex2. Each threshold cycle $\left(C_{t}\right.$ value) was calculated using the QuantStudio 12K Flex Real-Time PCR System (Thermo Fisher Scientific).

\section{Statistical analysis}

Data are presented as the mean \pm SD unless otherwise indicated. A two-way analysis of variance (ANOVA) was used to examine significant differences for each concentration between both groups. Unpaired $t$-tests were used to determine differences between two groups of continuous variables. Unpaired t-test and one-way ANOVA were used to determine differences within groups of continuous variables. Bonferroni correction was used to correct for multiplicity of comparisons among groups. P-values $<0.05$ were considered significant. All statistical analyses were performed using SPSS version 22.0 for windows (IBM)

\section{SUPPLEMENTAL MATERIAL}

Supplemental material is available for this article.

\section{COMPETING INTEREST STATEMENT}

All authors except for Y. Tomari are current employees of Kyowa Kirin Co., Ltd. Patents related to this research have been granted (US patent numbers: 10378011 and 10342819).

\section{ACKNOWLEDGMENTS}

We thank Yasuhiro Suzuki, Keiji Uehara, Hiroe Toki, Kazumasa Hasegawa, Masayoshi Nakoji, Makiko Hori, Saori Takahashi, Toshiyuki Atsumi, Koji Negishi, Yoshisuke Nakasato, Tetsuo Yoshida, and Atsushi Miwa for fruitful discussions and technical support. We are grateful to all members of the Tomari laboratory for fruitful discussions on research. This work was supported by Kyowa Kirin Co. Ltd.

Author contributions: F.S., T.O., T.H., Y. Takayama, H.M., M.S., J.Y., and J.S. conceptualized the study. F.S., Y.Tomari, and J.S. supervised the study. T. Nishikawa, T. Nakajima, T.S., Y.K., and J.Y. designed and synthesized all compounds. T.O. and A.S. performed the in silico analysis. H.M., Y. Takahashi, K.H., M.S., and J.S performed the protein preparation and structure determination by X-ray crystallography. Y. Takayama performed the NMR experiments. F.S., T.H., and A.M. designed and conducted in vitro and in vivo experiments. F.S. drafted the manuscript. F.S., T.O., T.H., Y. Takayama, H.M., M.S., J.Y., and Y.Tomari revised the manuscript.

Received October 27, 2019; accepted November 5, 2020.

\section{REFERENCES}

Adams D, Gonzalez-Duarte A, O'Riordan WD, Yang C-C, Ueda M, Kristen AV, Tournev I, Schmidt HH, Coelho T, Berk JL, et al. 2018. Patisiran, an RNAi therapeutic, for hereditary transthyretin amyloidosis. $N$ Engl J Med 379: 11-21. doi:10.1056/ NEJMoa1716153

Amarzguioui M, Prydz H. 2004. An algorithm for selection of functional siRNA sequences. Biochem Biophys Res Commun 316: 10501058. doi:10.1016/j.bbrc.2004.02.157

Brechin V, Shinohara F, Saito J, Seitz H, Tomari Y. 2021. Mechanistic analysis of the enhanced RNAi activity by 6-mCEPh-purine at the $5^{\prime}$ end of the siRNA guide strand. RNA 27: 151-162 (this issue). doi:10.1261/rna.073775.119

Chiu Y, Rana TM. 2003. siRNA function in RNAi: a chemical modification analysis. RNA 9: 1034-1048. doi:10.1261/rna.5103703

Coles AH, Turanov AA, Godinho BMDC, Echeverria D, Alterman JF, Roux L, Haraszti RA, Khvorova A, Aronin N. 2017. 5'-vinylphosphonate improves tissue accumulation and efficacy of conjugated siRNAs in vivo. Nucleic Acids Res 45: 7581-7592. doi:10.1093/ nar/gkx507

Czauderna F, Fechtner M, Dames S, Aygün H, Klippel A, Pronk GJ, Giese K, Kaufmann J. 2003. Structural variations and stabilising modifications of synthetic siRNAs in mammalian cells. Nucleic Acids Res 31: 2705-2716. doi:10.1093/nar/gkg393

Deleavey GF, Damha MJ. 2012. Designing chemically modified oligonucleotides for targeted gene silencing. Chem Biol 19: 937-954. doi:10.1016/j.chembiol.2012.07.011

Elkayam E, Joshua-Tor L, Parmar R, Brown CR, Willoughby JL, Theile CS, Manoharan M. 2017. siRNA carrying an (E)-vinylphosphonate moiety at the $5^{\prime}$ end of the guide strand augments gene silencing by enhanced binding to human Argonaute- 2 . Nucleic Acids Res 45: 3528-3536. doi:10.1093/nar/gkw1171

Felice KMM, Salzman DWW, Shubert-Coleman J, Jensen KPP, Furneaux HMM. 2009. The $5^{\prime}$ terminal uracil of let-7a is critical for the recruitment of mRNA to Argonaute2. Biochem $J$ 422: 329-341. doi:10.1042/BJ20090534

Frank F, Sonenberg N, Nagar B. 2010. Structural basis for 5'-nucleotide base-specific recognition of guide RNA by human AGO2. Nature 465: 818-822. doi:10.1038/nature09039

Hannon GJ, Rossi JJ. 2004. Unlocking the potential of the human genome with RNA interference. Nature 431: 371-378. doi:10.1038/ nature 02870

Haraszti RA, Miller R, Didiot M-C, Biscans A, Alterman JF, Hassler MR, Roux L, Echeverria D, Sapp E, DiFiglia M, et al. 2018. Optimized cholesterol-siRNA chemistry improves productive loading onto extracellular vesicles. Mol Ther 26: 1973-1982. doi:10.1016/j.ymthe .2018.05.024

Hu HY, Yan Z, Xu Y, Hu H, Menzel C, Zhou YH, Chen W, Khaitovich P. 2009. Sequence features associated with microRNA strand selection in humans and flies. BMC Genomics 10: 413. doi:10.1186/ 1471-2164-10-413

Humphrey W, Dalke A, Schulten K. 1996. VMD: visual molecular dynamics. J Mol Graph 14: 33-38. doi:10.1016/0263-7855(96) 00018-5

Jackson AL, Burchard J, Leake D, Reynolds A, Schelter J, Guo J, Johnson JM, Lim L, Karpilow J, Nichols K, et al. 2006. Position-specific chemical modification of siRNAs reduces "off-target" transcript silencing. RNA 12: 1197-1205. doi:10.1261/rna.30706

Kawamata T, Tomari Y. 2010. Making RISC. Trends Biochem Sci 35: 368-376. doi:10.1016/j.tibs.2010.03.009

Kuboyama T, Yagi K, Naoi T, Era T, Yagi N, Nakasato Y, Yabuuchi H, Takahashi S, Shinohara F, Iwai H, et al. 2019. Simplifying the chemical structure of cationic lipids for siRNA-lipid nanoparticles. ACS Med Chem Lett 10: 749-753. doi:10.1021/acsmedchemlett $8 \mathrm{~b} 00652$

Leslie AGW. 2006. The integration of macromolecular diffraction data. Acta Crystallogr Sect D Biol Crystallogr 62: 48-57. doi:10.1107/ S0907444905039107 
Lima WF, Prakash TP, Murray HM, Kinberger GA, Li W, Chappell AE, Li CS, Murray SF, Gaus H, Seth PP, et al. 2012. Single-stranded siRNAs activate RNAi in animals. Cell 150: 883-894. doi:10 .1016/j.cell.2012.08.014

Nakanishi K, Weinberg DE, Bartel DP, Patel DJ. 2012. Structure of yeast Argonaute with guide RNA. Nature 486: 368-374. doi:10 $.1038 /$ nature 11211

Onizuka K, Zheng Y, Mac S, Ball-Jones AA, Beal PA, Lam W, IbarraSoza JM, Tantillo DJ, Ly D, Harrison JG. 2013. Short interfering RNA guide strand modifiers from computational screening. J Am Chem Soc 135: 17069-17077. doi:10.1021/ja4079754

Prakash TP, Kinberger GA, Murray HM, Chappell A, Riney S, Graham MJ, Lima WF, Swayze EE, Seth PP. 2016. Synergistic effect of phosphorothioate, 5'-vinylphosphonate and GalNAc modifications for enhancing activity of synthetic siRNA. Bioorganic Med Chem Lett 26: 2817-2820. doi:10.1016/j.bmcl.2016.04.063

Reynolds A, Leake D, Boese Q, Scaringe S, Marshall WS, Khvorova A. 2004. Rational siRNA design for RNA interference. Nat Biotechnol 22: 326-330. doi:10.1038/nbt936

Schirle NT, MacRae IJ. 2012. The crystal structure of human Argonaute2. Science 336: 1037-1040. doi:10.1126/science .1221551

Schirle NT, Sheu-Gruttadauria J, MacRae IJ. 2014. Structural basis for microRNA targeting. Science 346: 608-613. doi:10.1126/science .1258040

Setten RL, Rossi JJ, Ping HS. 2019. The current state and future directions of RNAi-based therapeutics. Nat Rev Drug Discov 18: 421446. doi:10.1038/s41573-019-0017-4

Song JJ, Smith SK, Hannon GJ, Joshua-Tor L. 2004. Crystal structure of argonaute and its implications for RISC slicer activity. Science 305: 1434-1437. doi:10.1126/science.1102514

Suter SR, Sheu-Gruttadauria J, Schirle NT, Valenzuela R, BallJones AA, Onizuka K, Macrae IJ, Beal PA. 2016. Structure-guided control of siRNA off-target effects. J Am Chem Soc 138: 86678669. doi:10.1021/jacs.6b06137

Ui-Tei K, Naito Y, Takahashi F, Haraguchi T, Ohki-Hamazaki H, Juni A, Ueda R, Saigo K. 2004. Guidelines for the selection of highly effective siRNA sequences for mammalian and chick RNA interference. Nucleic Acids Res 32: 936-948. doi:10.1093/nar/gkh247

Vagin A, Teplyakov A. 1997. MOLREP: an automated program for molecular replacement. J Appl Crystallogr 30: 1022-1025. doi:10 $.1107 /$ S0021889897006766

Wang Y, Sheng G, Juranek S, Tuschl T, Patel DJ. 2008. Structure of the guide-strand-containing argonaute silencing complex. Nature 456: 209-213. doi:10.1038/nature07315

Yagi N, Manabe I, Tottori T, Ishihara A, Ogata F, Jong HK, Nishimura S, Fujiu K, Oishi Y, Itaka K, et al. 2009. A nanoparticle system specifically designed to deliver short interfering RNA inhibits tumor growth in vivo. Cancer Res 69: 6531-6538. doi:10.1158/ 0008-5472.CAN-08-3945

Yamauchi M, Kusano H, Saito E, Iwata T, Nakakura M, Kato Y, Uochi T, Akinaga S, Aoki N. 2006. Improved formulations of antisense oligodeoxynucleotides using wrapped liposomes. J Control Release 114: 268-275. doi:10.1016/j.jconrel.2006.05.025

Yoda M, Kawamata T, Paroo Z, Ye X, Iwasaki S, Liu Q, Tomari Y. 2010. ATP-dependent human RISC assembly pathways. Nat Struct Mol Biol 17: 17-24. doi:10.1038/nsmb.1733

Yuan YR, Pei Y, Ma JB, Kuryavyi V, Zhadina M, Meister G, Chen HY, Dauter Z, Tuschl T, Patel DJ. 2005. Crystal structure of A. aeolicus argonaute, a site-specific DNA-guided endoribonuclease, provides insights into RISC-mediated mRNA cleavage. Mol Cell 19: 405-419. doi:10.1016/j.molcel.2005.07.011

Zlatev I, Foster DJ, Liu J, Charisse K, Brigham B, Parmar RG, Jadhav V, Maier MA, Rajeev KG, Egli M, et al. 2016. 5'-C-malonyl RNA: small interfering RNAs modified with $5^{\prime}$-monophosphate bioisostere demonstrate gene silencing activity. ACS Chem Biol 11: 953960. doi:10.1021/acschembio.5b00654 

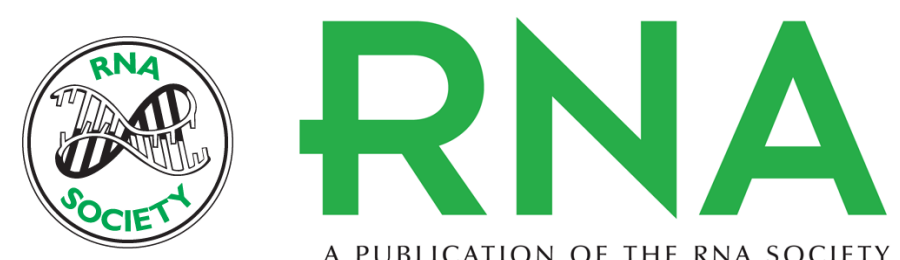

A PUBLICATION OF THE RNA SOCIETY

\section{siRNA potency enhancement via chemical modifications of nucleotide bases at the 5 '-end of the siRNA guide strand}

Fumikazu Shinohara, Taiji Oashi, Toshimasa Harumoto, et al.

RNA 2021 27: 163-173 originally published online November 11, 2020

Access the most recent version at doi:10.1261/rna.073783.119

\section{Supplemental http://rnajournal.cshlp.org/content/suppl/2020/11/11/rna.073783.119.DC1 \\ Material}

Related Content

Mechanistic analysis of the enhanced RNAi activity by 6-mCEPh-purine at the 52 end of the siRNA guide strand

Vincent Brechin, Fumikazu Shinohara, Jun-ichi Saito, et al.

RNA February , 2021 27: 151-162

References This article cites 36 articles, 8 of which can be accessed free at:

http://rnajournal.cshlp.org/content/27/2/163.full.html\#ref-list-1

Articles cited in:

http://rnajournal.cshlp.org/content/27/2/163.full.html\#related-urls

Creative This article is distributed exclusively by the RNA Society for the first 12 months after the

Commons full-issue publication date (see http://rnajournal.cshlp.org/site/misc/terms.xhtml). After 12

License months, it is available under a Creative Commons License (Attribution-NonCommercial 4.0 International), as described at http://creativecommons.org/licenses/by-nc/4.0/.

Email Alerting
Service

Receive free email alerts when new articles cite this article - sign up in the box at the top right corner of the article or click here. 